ISSN 0103-9954

\title{
DISTÚRBIOS NUTRICIONAIS INDUZIDOS PELA ADUBAÇÃO DE FÓSFORO E FERRO EM PLANTAS JOVENS DE GRÁPIA (Apuleia leiocarpa)
}

\author{
NUTRITIONAL DISTURBANCE INDUCED BY PHOSPHORUS AND IRON FERTILIZATION ON \\ YOUNG PLANTS OF GRÁPIA (Apuleia leiocarpa)
}

\author{
Evandro Luiz Missio $^{1}$ Fernando Teixeira Nicoloso ${ }^{2}$
}

\begin{abstract}
RESUMO
A grápia (Apuleia leiocarpa Vog. Macbride) é uma espécie florestal nativa de grande interesse madeireiro, encontrando-se, atualmente, bastante dizimada. Em trabalhos anteriores, foi observado que as folhas novas de plantas jovens de grápia apresentaram sintomas visuais indicativos de deficiência de Fe na presença de doses crescentes de P. O presente trabalho teve como objetivo caracterizar os efeitos da interação da adubação de $\mathrm{P}$ e Fe no balanço nutricional e no crescimento de plantas jovens de grápia cultivadas num ARGISSOLO VERMELHO Distrófico arênico, sob condições de casa de vegetação. Os tratamentos consistiram de uma combinação bifatorial (2x3) completa, com dois níveis de adubação de fósforo (60 e 180 $\left.\mathrm{mg} \mathrm{kg}^{-1}\right)$ e três níveis de ferro $\left(0,6\right.$ e $\left.12 \mathrm{mg} \mathrm{kg}^{-1}\right)$; além disso, realizou-se adubação complementar de $\mathrm{N}, \mathrm{K}$, $\mathrm{Ca}$ e $\mathrm{Mg}$ em todos tratamentos. A análise de crescimento das plantas foi realizada mensalmente, considerando a altura de planta, diâmetro do caule e número de folhas por planta. Aos 150 dias após a emergência das plantas, avaliaram-se ainda a massa seca de raízes, do caule, das folhas e total da planta, comprimento das raízes, comprimento radicular específico, número de folhas caídas, relação entre a massa seca de raízes e da parte aérea e a concentração de $\mathrm{P}, \mathrm{Fe}, \mathrm{Cu}$ e $\mathrm{Zn}$ nos tecidos da planta. A relação de concentração entre o $\mathrm{P}$ e os micronutrientes $\mathrm{Fe}, \mathrm{Cu}$ e $\mathrm{Zn}$ é mais apropriada na avaliação do estado nutricional da grápia que a análise da concentração absoluta desses elementos nos tecidos. A alta disponibilidade de $\mathrm{P}$ no solo causou deficiência de $\mathrm{Fe}, \mathrm{Cu}$ e $\mathrm{Zn}$ nas plantas de grápia. O aumento da disponibilidade de $\mathrm{Fe}$, ocasionado pela adubação desse elemento, ou pela diminuição do $\mathrm{pH}$ do solo, induzida pela adubação com outros nutrientes, provocou decréscimo nas concentrações de $\mathrm{Cu}$ e $\mathrm{Zn}$ nas raízes. Na presença de $180 \mathrm{mg}$ de $\mathrm{P} \mathrm{kg}^{-1}$ de solo, a aplicação de $12 \mathrm{mg} \mathrm{de} \mathrm{Fe} \mathrm{kg}^{-1}$ de solo, na forma de Fe-EDTA, diminuiu a clorose foliar e aumentou o crescimento de plantas jovens de grápia.
\end{abstract}

Palavras-chave: grápia; fósforo; ferro; cobre; zinco.

\section{ABSTRACT}

Grápia (Apuleia leiocarpa Vog. Macbride) is an important native forest species that has been in an extinction process. In previous studies with young plants of grápia, visual Fe-deficiency symptoms in new leaves were related with increasing $P$ fertilization. The aim of this study was to characterize the effects of the interaction between $\mathrm{P}$ and $\mathrm{Fe}$ fertilization on nutritional balance and growth of young plants of grápia cultivated in a Paleaudalf soil, under glasshouse conditions. The treatments consisted of a bifactorial scheme (2x3), represented by the combination of two levels of $P$ fertilization (60 and $\left.180 \mathrm{mg} \mathrm{kg}^{-1}\right)$ and three levels of $\mathrm{Fe}\left(0,6\right.$, and $\left.12 \mathrm{mg} \mathrm{kg}^{-1}\right)$; in addition a supplementary fertilization of $\mathrm{N}, \mathrm{K}, \mathrm{Ca}$ and $\mathrm{Mg}$ were carried out for all treatments. The plant growth was analysed monthly through plant height, stem diametrer, and number of leaves measurement. After 150 days of seedling emergence, the dry weight of roots, stem, leaves, and the whole plant, length of the root system, specific root length, number of abscissed leaves, root/shoot dry weight ratio, and $\mathrm{P}, \mathrm{Fe}, \mathrm{Cu}$ and $\mathrm{Zn}$ contents in plant tissue were analyzed. The ratio of $\mathrm{P} / \mathrm{Fe}, \mathrm{P} / \mathrm{Cu}$, and $\mathrm{P} / \mathrm{Zn}$ was more suitable to evaluate the nutritional status of young plants than the analysis of the absolute content of those nutrients in the tissues. High $\mathrm{P}$ availability in soil caused $\mathrm{Fe}, \mathrm{Cu}$ and $\mathrm{Zn}$ deficiency in plants of grápia. Increasing the availability of $\mathrm{Fe}$, due to Fe fertilization, or by decreasing of soil $\mathrm{pH}$, induced by fertilization of several nutrients, caused decreasing on $\mathrm{Cu}$ and $\mathrm{Zn}$ content in roots. In the presence of $180 \mathrm{mg}$ of $\mathrm{P} \mathrm{kg}$ of soil, the addition of $12 \mathrm{mg}$ of $\mathrm{Fe} \mathrm{kg}^{-1}$ of soil, as Fe-EDTA, decreased leaf chlorosis and increased the growth of young plants of grápia.

Key words: grápia; phosphorus; iron; copper; zinc.

1. Engenheiro Agrônomo, MSc., Técnico da FEPAGRO no município de Júlio de Castilhos (RS).

2. Engenheiro Agrônomo, Ph.D., Professor Adjunto do Departamento de Biologia, Centro de Ciências Naturais e Exatas, Universidade Federal de Santa Maria, CEP 97119-390, Santa Maria (RS). nicoloso@base.ufsm.br

Recebido para publicação em 6/08/2002 e aceito em 20/12/2005. 


\section{INTRODUÇÃO}

A grápia (Apuleia leiocarpa Vog. Macbride), pertencente à família Leguminosae, é uma espécie florestal que apresenta ampla distribuição geográfica no território brasileiro, porém atualmente se acha bastante descontínua, em conseqüência da devastação intensa das matas e à falta de reposição por meio do reflorestamento (Mattos e Guaranha, 1983).

Segundo Brasil (1973), no estado do Rio Grande do Sul, a área ocupada por essa espécie é pequena, encontrando-se nas partes mais altas do noroeste do planalto, onde o solo é fértil, profundo e úmido, e em pontos esparsos na Depressão Central. Na região de maior dispersão, a grápia ocorre em LATOSSOLO VERMELHO Distroférrico típico, e também em NEOSSOLO LITÓLICO Eutrófico chernossólico e CHERNOSSOLO ARGILÚVICO Férrico típico. Segundo Reitz et al. (1988), diante das suas múltiplas aplicações, a grápia deve ser considerada como uma das mais valiosas madeiras do Estado e, conseqüentemente, merece uma atenção especial nos estudos sobre a viabilidade de seu reflorestamento em larga escala.

Estudos realizados em plantas jovens de grápia por Fogaça (1999), demonstraram que a concentração de $\mathrm{Fe}$ no caule apresentou resposta linear negativa à adubação isolada de $\mathrm{N}$ e quadrática ao $\mathrm{P}$, com dose de máxima eficiência técnica estimada (DMET) de $40 \mathrm{mg}$ de $\mathrm{P} \mathrm{kg}^{-1}$ de um ARGISSOLO VERMELHO Distrófico arênico. Missio (2002), testando doses mais elevadas de adubação fosfatada em combinação com enxofre, observou que a produção da biomassa das plantas jovens de grápia respondeu à interação desses nutrientes, com DMET de, respectivamente, 204,2 e $16,0 \mathrm{mg} \mathrm{kg}^{-1}$ de solo. Por outro lado, também constatou que a adubação de $\mathrm{P}$ acima de $120 \mathrm{mg} \mathrm{kg}^{-1}$ induziu o aparecimento de clorose foliar típica da deficiência de Fe.

O balanceamento nutricional nos tecidos da planta é um aspecto importante a ser considerado na obtenção de uma relação favorável entre todos os nutrientes minerais bem como com outros elementos químicos (Marschner, 1995). Algumas plantas desenvolvem clorose típica de deficiência de Fe quando existe alta disponibilidade de P no solo ou na solução nutritiva (Biddulph e Woodbridge, 1952; Watanabe et al., 1965). Na presença de $2 \mathrm{mg}$ de $\mathrm{Fe} \mathrm{L}^{-1}$ de solução nutritiva, Watanabe et al. (1965) observaram que plantas de milho (Zea mays L.) sofreram redução no crescimento, bem como apresentaram-se extremamente deficientes em Fe, quando o nível de $\mathrm{P}$ aumentou de 6,2 para $18,6 \mathrm{mg} \mathrm{L}^{-1}$. Nesse mesmo trabalho, a clorose de Fe e a redução do rendimento de grãos foram corrigidas pelo aumento da dose de FeEDDHA (de 2 para $4 \mathrm{mg} \mathrm{L}^{-1}$ ). Interessantemente, a concentração de $\mathrm{Fe}$ na parte aérea da planta não foi alterada pela dose de $\mathrm{Fe}$, mas a relação de concentração do $\mathrm{P} / \mathrm{Fe}$ nos tecidos diminuiu de 158 para 61 . Assim, um aumento no suprimento de $\mathrm{Fe}^{3+}$ quelatizado preveniu o efeito do excesso de $\mathrm{P}$.

Num levantamento sobre a interação do $\mathrm{P}$ e do $\mathrm{Fe}$, Olsen (1977) relata que alguns experimentos indicam a existência de fosfato de ferro precipitado externamente às raízes. Entretanto, esse mesmo autor salienta que a interação desses nutrientes, provocando a clorose de $\mathrm{Fe}$, parece ser causada pela imobilização interna do Fe, provavelmente pela formação de fosfato de Fe. Várias outras investigações têm indicado que as folhas podem mostrar sintomas de deficiência de Fe mesmo que contenham concentrações de Fe mais altas do que as folhas verdes (Carter, 1980; Malavolta, 1980; Mengel e Malissiovas, 1981; SAHU et al., 1987).

Plantas de feijão (Phaseolus vulgaris L.), visualmente deficientes em $\mathrm{Fe}$, apresentaram conteúdo total elevado desse elemento nas folhas (em torno de $500 \mathrm{mg} \mathrm{kg}^{-1}$ ), enquanto que folhas de plântulas normais possuíam em torno de $400 \mathrm{mg} \mathrm{kg}^{-1}$ (Malavolta, 1980). Esses dados sugeriram que parte do Fe foi inativado nas plantas que apresentaram sintomas de deficiência, sendo atribuído esse evento à alta relação $\mathrm{P} / \mathrm{Fe}$ nas plantas cloróticas.

O presente trabalho teve como objetivo caracterizar os efeitos da interação da adubação de $\mathrm{P}$ e Fe no balanço nutricional e no crescimento de plantas jovens de grápia (Apuleia leiocarpa Vog. Macbride).

\section{MATERIAL E MÉTODOS}

Foi conduzido um experimento na casa de vegetação não-climatizada do Departamento de Fitotecnia do Centro de Ciências Rurais, na Universidade Federal de Santa Maria, RS. Foram testados seis tratamentos em esquema bifatorial completo $(2 \times 3)$, representados por dois níveis de adubação de fósforo (60 e $180 \mathrm{mg}$ 
$\left.\mathrm{kg}^{-1}\right)$, na forma de $\mathrm{Ca}\left(\mathrm{H}_{2} \mathrm{PO}_{4}\right)_{2}$, e três níveis de adubação de ferro $\left(0,6,12 \mathrm{mg} \mathrm{kg}^{-1}\right)$, na forma de Fe-EDTA. $\mathrm{O}$ delineamento experimental usado foi de tratamentos inteiramente casualizados, com cinco repetições. A parcela experimental foi constituída de um vaso com 3,5 $\mathrm{kg}$ de terra fina seca ao ar e duas plantas, as quais foram submetidas a rodízio periódico para evitar algum efeito de localização na casa de vegetação.

Realizou-se uma adubação suplementar de $\mathrm{N}\left(60 \mathrm{mg} \mathrm{kg}^{-1}\right)$, de $\mathrm{K}\left(80 \mathrm{mg} \mathrm{kg}^{-1}\right)$, de Ca (39 a $116 \mathrm{mg}$ $\left.\mathrm{kg}^{-1}\right)$ e de $\mathrm{Mg}\left(19\right.$ a $\left.58 \mathrm{mg} \mathrm{kg}^{-1}\right)$. As fontes de nutrientes foram $\mathrm{KNO}_{3}, \mathrm{NH}_{4} \mathrm{NO}_{3}, \mathrm{NaNO}_{3}, \mathrm{Ca}_{2}\left(\mathrm{H}_{2} \mathrm{PO}_{4}\right)_{2} \mathrm{e}$ $\mathrm{MgCl}_{2}$. Manteve-se a relação $\mathrm{N}-\mathrm{NO}_{3}{ }^{-}$e $\mathrm{N}-\mathrm{NH}_{4}{ }^{+}$em 2:1 bem como a de Ca e $\mathrm{Mg}$ em 2:1. Todos nutrientes foram aplicados na forma de solução nutritiva em dose única, dois dias após a semeadura.

O solo utilizado no experimento foi coletado de 0 a $65 \mathrm{~cm}$ de profundidade do horizonte A de um ARGISSOLO VERMELHO Distrófico arênico no município de Santa Maria, RS. Antes da instalação do experimento e no término, aos 150 dias após a emergência das plantas (DAE), realizou-se a análise química do solo (Tabela 1).

TABELA 1: Características químicas do solo sem e com adubação. As amostras de solo adubado foram coletadas aos 150 dias após a emergência das plantas de grápia, submetidas a diferentes níveis de adubação de $\mathrm{P}$ e Fe.

TABLE 1: Chemical features of the soil without and with fertilization. Samples of the fertilized soil were taken at 150 days after emergence of grápia plants under different levels of $\mathrm{P}$ and $\mathrm{Fe}$ fertilization.

\begin{tabular}{|c|c|c|c|c|c|c|c|}
\hline \multirow[t]{2}{*}{ Elementos } & \multicolumn{7}{|c|}{ Doses de $\mathrm{P}-\mathrm{Fe}\left(\mathrm{mg} \mathrm{kg}^{-1}\right)$} \\
\hline & $0-0^{1}$ & $60-0$ & $60-6$ & $60-12$ & $180-0$ & $180-6$ & $180-12$ \\
\hline $\mathrm{pH}-\mathrm{H}_{2} \mathrm{O}(1: 1)$ & 4,7 & 4,0 & 4,2 & 4,1 & 4,2 & 4,2 & 4,2 \\
\hline $\mathrm{P}^{2}\left(\mathrm{mg} \mathrm{L}^{-1}\right)$ & 4,8 & 32 & 31 & 33 & 69 & 69 & 69 \\
\hline $\mathrm{K}^{2}\left(\mathrm{mg} \mathrm{L}^{-1}\right)$ & 22 & 106 & 112 & 100 & 104 & 96 & 76 \\
\hline $\mathrm{Ca}^{3}\left(\mathrm{cmol}_{\mathrm{c}} \mathrm{L}^{-1}\right)$ & 0,8 & 0,9 & 0,9 & 0,8 & 1,4 & 1,3 & 1,4 \\
\hline $\mathrm{Mg}^{3}\left(\mathrm{cmol}_{\mathrm{c}} \mathrm{L}^{-1}\right)$ & 0,2 & 0,4 & 0,5 & 0,4 & 0,9 & 0,8 & 0,8 \\
\hline M.O. ${ }^{4}(\%)$ & 1,0 & 1,0 & 0,9 & 0,9 & 0,9 & 0,9 & 0,9 \\
\hline Saturação de bases (V\%) & 21 & 33 & 32 & 31 & 44 & 38 & 45 \\
\hline Saturação de $\mathrm{Al}^{+3}(\mathrm{~m} \%)$ & 51 & 41 & 37 & 45 & 24 & 28 & 25 \\
\hline $\mathrm{Cu}^{5}\left(\mathrm{mg} \mathrm{L}^{-1}\right)$ & 0,9 & 0,8 & 0,8 & 1,1 & 0,8 & 0,7 & 1,3 \\
\hline $\mathrm{Zn}^{5}\left(\mathrm{mg} \mathrm{L}^{-1}\right)$ & 2,4 & 3,3 & 3,5 & 3,3 & 4,4 & 4,1 & 5,5 \\
\hline $\mathrm{Fe}^{6}\left(\mathrm{mg} \mathrm{L}^{-1}\right)$ & 32 & 54 & 54 & 59 & 68 & 66 & 73 \\
\hline $\mathrm{Mn}^{7}\left(\mathrm{mg} \mathrm{L}^{-1}\right)$ & 33 & 35 & 35 & 36 & 39 & 37 & 39 \\
\hline
\end{tabular}

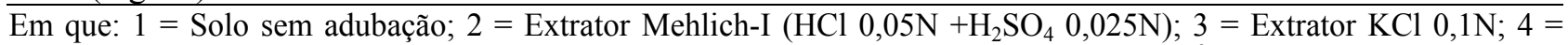
Oxidação em solução sulfocrômica a quente e determinação por espectrofotometria com $\mathrm{Cr}^{3+} ; 5=$ Extrator $\mathrm{HCl} 0,1 \mathrm{~N} ; 6$ $=$ Extrator oxalato de amônio $0,2 \mathrm{M}$ a pH $=3,0 ; 7=$ Extrator $\mathrm{KCl} 1 \mathrm{~N}+\mathrm{HCl} 0,1 \mathrm{~N}$.

Os vasos foram pintados externamente com tinta branca para evitar o aquecimento excessivo por causa da incidência de luz solar e, internamente, foram forrados com sacos plásticos contendo o solo, evitando a perda de água e nutrientes pela drenagem. Para reposição da água evapotranspirada foi realizada irrigação, com água deionizada, sobre a superfície ou através de canos PVC perfurados e introduzidos no solo, mantendo-se a umidade do solo entre 40 e $60 \%$ da capacidade de campo, segundo método descrito por Embrapa (1979), por meio de aferições diárias por pesagem.

As sementes receberam escarificação química com $\mathrm{H}_{2} \mathrm{SO}_{4}$ concentrado, segundo Nicoloso et al. (1997), seguido de tratamento com solução fungicida à base de Benlate (Benomyl) a 0,2\%. Após procedeuse à semeadura de quatro sementes diretamente nos vasos. Após a emergência das plântulas, realizou-se a seleção destas deixando-se duas por vaso.

A análise do crescimento das plantas foi realizada mensalmente, iniciando-se aos 30 e finalizado aos 150 DAE, perfazendo um total de cinco avaliações, nas quais, foram avaliadas o diâmetro do caule, altura da planta e número de folhas remanescentes. Apenas aos 150 DAE, avaliaram-se ainda o comprimento de raízes, segundo o método descrito por Tennant (1975), comprimento radicular específico, a massa seca de raízes, do caule, de folhas e total da planta, relação entre a massa seca de raízes e da parte aérea, número de 
folhas caídas e a concentração de $\mathrm{P}, \mathrm{Fe}, \mathrm{Cu}$ e $\mathrm{Zn}$ nos tecidos da planta, segundo a metodologia descrita por Tedesco et al. (1995).

O experimento foi instalado no dia 29 de setembro de 2000, e a emergência da plântulas foi observada no dia 4 de outubro de 2000. Durante a condução do experimento foram feitas aplicações de inseticida via foliar para o controle da trips, utilizando-se Confidor (Imidacloprid) na concentração de 0,6 $\mathrm{g} \mathrm{L}^{-1}$.

A análise estatística dos resultados observados baseou-se na comparação de médias e análise de regressão, ao nível de probabilidade de erro de $5 \%$.

\section{RESULTADOS E DISCUSSÃO}

\section{Efeito isolado da adubação de fósforo}

A altura de planta, do $30^{\circ}$ ao $150^{\circ}$ dia após a emergência das plantas (DAE), o diâmetro do caule, aos 90 DAE, e o número de folhas por planta, aos 60 e 120 DAE, apresentaram efeito isolado à adubação fosfatada (Tabela 2).

TABELA 2: Altura de plantas, diâmetro do caule e número de folhas de plantas jovens de grápia, cultivadas em ARGISSOLO VERMELHO Distrófico arênico com adição de 60 e $180 \mathrm{mg}$ de $\mathrm{P}$ por $\mathrm{kg}^{-1}$ de solo, aos 30, 60, 90, 120 e 150 dias após a emergência (DAE).

TABLE 2: Plant height, stem diameter and number of leaves of young plants of grápia, grown in a Paleaudalf soil with addition of 60 and $180 \mathrm{mg}$ of $\mathrm{P} \mathrm{kg}^{-1}$ of soil, at $30,60,90,120$ and 150 days after emergence (DAE).

\begin{tabular}{|c|c|c|c|c|c|}
\hline \multirow{2}{*}{$\begin{array}{l}\text { Doses de P } \\
\left(\mathrm{mg} \mathrm{kg}^{-1}\right)\end{array}$} & \multicolumn{5}{|c|}{ Dias após emergência } \\
\hline & 30 & 60 & 90 & 120 & 150 \\
\hline & \multicolumn{5}{|c|}{ Altura de planta $(\mathrm{cm})$} \\
\hline 60 & $8,74 \mathrm{~b}$ & $15,08 \mathrm{~b}$ & $17,89 \mathrm{~b}$ & $21,75 \mathrm{~b}$ & $28,94 \mathrm{~b}$ \\
\hline \multirow[t]{2}{*}{180} & $9,12 \mathrm{a}$ & $19,09 \mathrm{a}$ & $23,34 \mathrm{a}$ & $29,59 \mathrm{a}$ & $41,10 \mathrm{a}$ \\
\hline & \multicolumn{5}{|c|}{ Diâmetro do caule $(\mathrm{cm})$} \\
\hline 60 & $0,11 \mathrm{a}$ & $0,16 \mathrm{a}$ & $0,17 \mathrm{~b}$ & $0,19 \mathrm{a}$ & * \\
\hline \multirow[t]{2}{*}{180} & $0,11 \mathrm{a}$ & $0,17 \mathrm{a}$ & $0,19 \mathrm{a}$ & $0,20 \mathrm{a}$ & * \\
\hline & \multicolumn{5}{|c|}{ Número de folhas planta ${ }^{-1}$} \\
\hline 60 & $4,86 \mathrm{a}$ & $6,57 \mathrm{~b}$ & $6,87 \mathrm{a}$ & $6,97 \mathrm{~b}$ & * \\
\hline 180 & $4,93 \mathrm{a}$ & $7,77 \mathrm{a}$ & $7,70 \mathrm{a}$ & $8,90 \mathrm{a}$ & * \\
\hline
\end{tabular}

Em que: Médias seguidas pela mesma letra na coluna não diferem entre si pelo teste de Tukey $(\mathrm{P}<0,05) ; *=$ Houve interação significativa entre as adubações de fósforo e ferro.

O comprimento radicular específico foi o único parâmetro de crescimento avaliado aos 150 DAE que não diferiu entre os níveis de adubação fosfatada (Tabela 3). Já a massa seca da parte aérea aumentou cerca de $100 \%$. Utilizando o mesmo tipo de solo, no cultivo da grápia, Nicoloso et al. (1999) observaram que a omissão isolada de $\mathrm{P}$ da adubação reduziu a biomassa em $92 \%$. Num estudo mais detalhado sobre o efeito da adubação NPK na produção de biomassa de plantas jovens de grápia, Nicoloso et al. (2001) constataram que a dose de máxima eficiência técnica estimada (DMET), para à adubação fosfatada, ficou acima de $80 \mathrm{mg} \mathrm{kg}^{-}$ 1 .

A razão entre a massa seca de raízes e da parte aérea (RRPA) diminuiu pelo aumento da adubação fosfatada (Tabela 3). É conhecido o fato que, na menor disponibilidade de P no solo, as plantas direcionam uma maior quantidade de fotossintatos para o crescimento das raízes (Marschner, 1995). Nicoloso et al. (2001), trabalhando com níveis de adubação de N, P e K em ARGISSOLO VERMELHO Distrófico arênico, observaram que o aumento da fertilização de $\mathrm{N}$ e P resultou na diminuição da RRPA, demonstrando que, na alta disponibilidade desses nutrientes para a planta, promove um maior crescimento da parte área em relação as raízes. 
TABELA 3: Efeito da adubação fosfatada na massa seca do caule, massa seca da parte aérea, comprimento radicular específico, razão entre a massa seca de raízes e da parte aérea e concentração de fósforo nos tecidos de grápia, aos 150 dias após a emergência da plantas, cultivadas num ARGISSOLO VERMELHO Distrófico arênico.

TABLE 3: Effect of the phosphate fertilization on dry mass of stem and aerial parts, specific root length, roots/aerial parts dry mass ratio, and phosphorus content of young plants of grápia, grown in a Paleaudalf soil, at 150 days after emergence.

\begin{tabular}{|c|c|c|c|c|}
\hline $\begin{array}{l}\text { Doses de } \\
\text { fósforo }\end{array}$ & \multicolumn{2}{|c|}{ Massa seca } & $\begin{array}{l}\text { Comprimento radicular } \\
\text { específico }\end{array}$ & $\begin{array}{c}\text { Razão de ms raiz/ } \\
\text { parte aérea }\end{array}$ \\
\hline \multirow[b]{2}{*}{$\mathrm{mg} \mathrm{kg}^{-1}$} & Caule & Parte aérea & \multirow[b]{2}{*}{$\mathrm{cm} \mathrm{g}^{-1}$} & \\
\hline & \multicolumn{2}{|c|}{$\left(\right.$ g planta $\left.^{-1}\right)$} & & \\
\hline 60 & $0,29 \mathrm{~b}$ & $0,82 \mathrm{~b}$ & $1061,3 \mathrm{a}$ & $0,65 \mathrm{a}$ \\
\hline 180 & $0,63 \mathrm{a}$ & $1,63 \mathrm{a}$ & $1001,9 \mathrm{a}$ & $0,38 \mathrm{~b}$ \\
\hline \multicolumn{5}{|c|}{ Fósforo no tecido } \\
\hline & \multicolumn{2}{|c|}{ Raiz } & Caule & Folha \\
\hline & & $\%$ & \\
\hline 60 & & & $0,04 \mathrm{~b}$ & $0,11 \mathrm{~b}$ \\
\hline 180 & \multicolumn{2}{|c|}{$0,16 \mathrm{a}$} & $0,11 \mathrm{a}$ & $0,36 \mathrm{a}$ \\
\hline
\end{tabular}

Em que: Médias seguidas pela mesma letra na colunal não diferem entre si pelo teste de Tukey $(\mathrm{P}<0,05)$.

Também não houve interação entre as adubações de $\mathrm{P}$ e $\mathrm{Fe}$ na concentração de $\mathrm{P}$ nos tecidos da planta. A concentração de P nas raízes, caule e folhas aumentou em, respectivamente, $100 \%, 175 \%$ e $227 \%$ pelo incremento da adubação fosfatada de 60 para $180 \mathrm{mg} \mathrm{kg}^{-1}$ (Tabela 3). Esse resultado demonstra um expressivo transporte do $\mathrm{P}$ em direção a parte aérea da planta numa situação de grande disponibilidade de $\mathrm{P}$, fato que corrobora as observações de Marschner (1995). Fogaça (1999), Nicoloso et al. (2001) e Missio (2002) também verificaram aumento na concentração de P nos tecidos da grápia, com efeito positivo no crescimento das plantas, pela adubação fosfatada, demonstrando que essa espécie florestal, quando cultivada num ARGISSOLO VERMELHO Distrófico arênico, é muito exigente em P.

\section{Efeito da interação entre a adubação de fósforo e de ferro}

Houve interação entre a maior dose de $\mathrm{P}$ e a adubação de $\mathrm{Fe}$ no crescimento das plantas aos 150 DAE (Figuras 1 e 2). Na presença de $180 \mathrm{mg}^{\text {de }} \mathrm{P} \mathrm{kg}^{-1}$ de solo, o diâmetro do caule (Figura 1a), número de folhas (Figura 1b), massa seca da folha (Figura 2a) e total da planta (Figura 2c) responderam de forma linear positiva à adubação de Fe. Já a massa seca de raízes (Figura 2b) e o comprimento de raízes (Figura 2d) responderam de forma quadrática, sendo que as doses de mínima eficiência técnica estimada à adubação de Fe foram de, respectivamente, $3,7 \mathrm{mg} \mathrm{kg}^{-1}$ e $4,3 \mathrm{mg} \mathrm{kg}^{-1}$. O número de folhas caídas por planta também respondeu de forma quadrática, em que a maior queda ocorreu na presença de $5,2 \mathrm{mg}$ de Fe $\mathrm{kg}^{-1} \mathrm{de}$ solo (Figura 1c). 

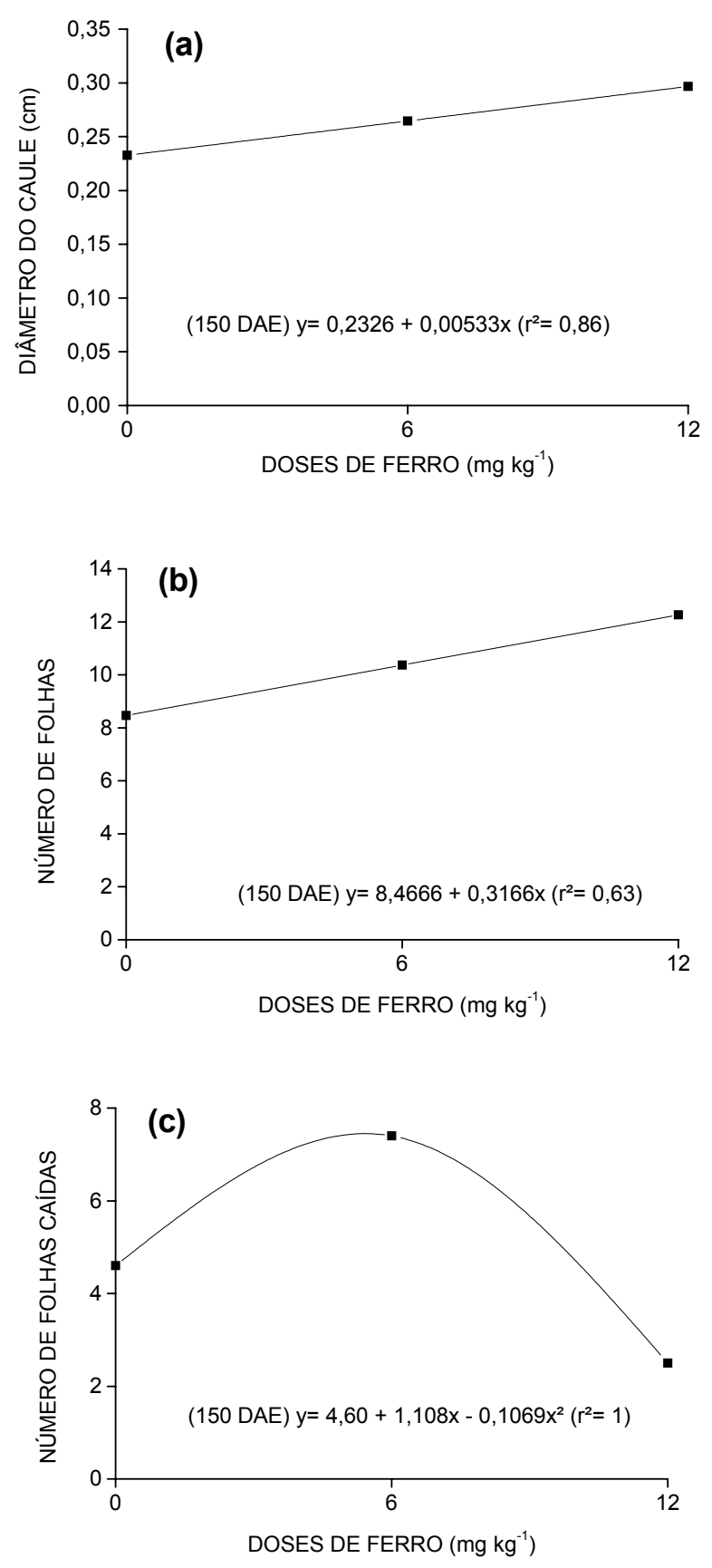

FIGURA 1: Efeito da adubação de Fe no diâmetro do caule (a), número de folhas remanescentes (b) e número de folhas caídas (c) de plantas jovens de grápia, cultivadas em ARGISSOLO VERMELHO Distrófico arênico na presença de $180 \mathrm{mg} \mathrm{kg}^{-1}$ de fósforo, aos 150 dias após a emergência (DAE).

FIGURE 1: Effect of the iron fertilization on stem diameter (a), number of remaining leaves (b), and number of abscissed leaves (c) of young plants of grápia, grown in a Paleaudalf soil, at 150 days after emergence. 

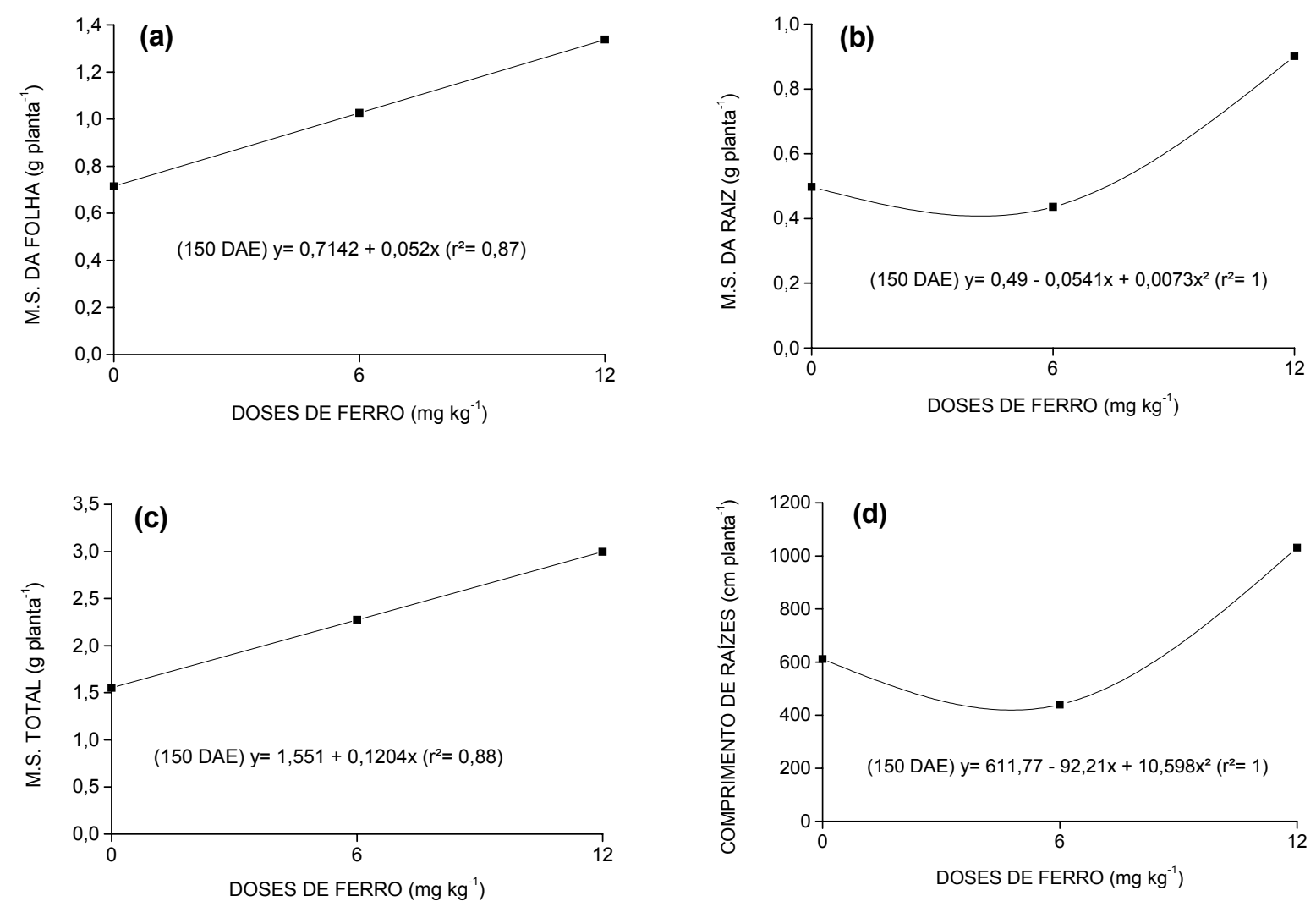

FIGURA 2: Efeito da adubação de Fe na massa seca da folha (a), massa seca de raízes (b), massa seca total da planta (c) e comprimento de raízes (d) de plantas jovens de grápia, cultivadas em ARGISSOLO VERMELHO Distrófico arênico na presença de $180 \mathrm{mg} \mathrm{kg}^{-1}$ de fósforo, aos 150 dias após a emergência (DAE).

FIGURE 2: Effect of the iron fertilization on dry mass of leaves (a), dry mass of roots (b), dry mass of the whole plant (c), and root length (d) of young plants of grápia, grown in a Paleaudalf soil, at 150 days after emergence.

Os resultados apresentados nas Figuras 1 e 2 mostram que, na maior dose de Fe utilizada (12 mg $\mathrm{kg}^{-1}$ ), associada a $180 \mathrm{mg}$ de $\mathrm{P} \mathrm{kg}^{-1}$ de solo, houve aumento para a maioria dos parâmetros de crescimento analisados. Além disso, constatou-se diminuição marcante nos sintomas visuais de clorose internerval típica da deficiência de Fe nas folhas jovens (Figura 3). Observações relatadas por Biddulph e Woodbridge (1952), Watanabe et al. (1965) e Olsen (1977) também mostram que a alta disponibilidade de P no substrato pode induzir deficiência de Fe nas plantas.

Em razão da pequena acumulação de massa seca pelos órgãos da planta, a determinação da concentração dos micronutrientes nos tecidos foi limitada a duas amostras compostas cujos resultados são apresentados como média aritmética (Tabela 4).

A concentração de Fe nas raízes foi de, respectivamente, 12,6 e 9,2 vezes maior daquela encontrada no caule e folhas (Tabela 4). Essa distribuição desigual do Fe nos órgãos de plantas jovens de grápia, cultivadas em ARGISSOLO VERMELHO Distrófico arênico, também foi constatada por Fogaça (1999) e Nicoloso et al. (1999), porém esses autores observaram diferenças menos acentuadas, sendo de, no máximo, 5,6 vezes. Tal diferença pode estar relacionada às distintas adubações realizadas nesses trabalhos. 

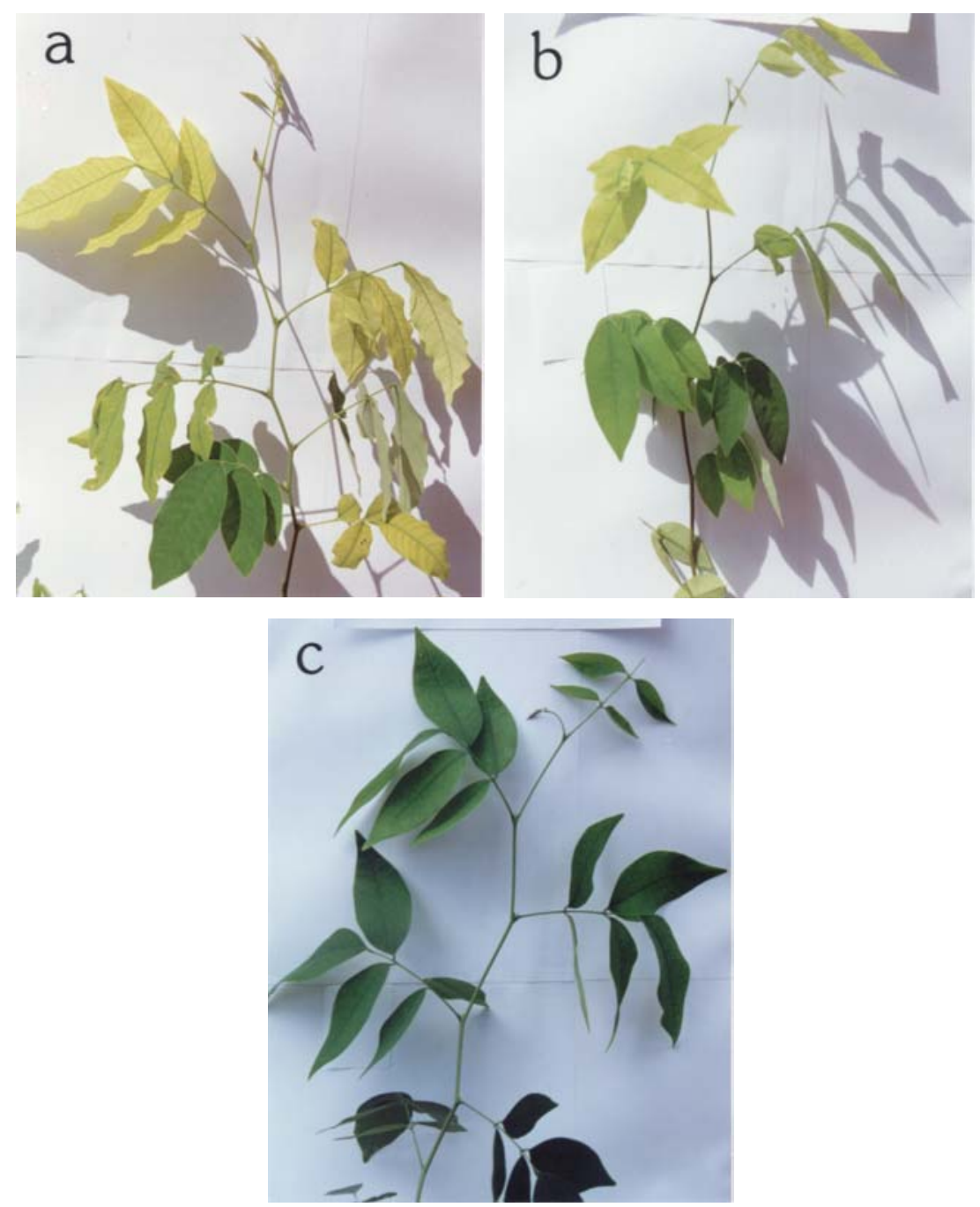

FIGURA 3: Coloração das folhas de plantas jovens de grápia fertilizadas com 0 (a), 6 (b) e 12 (c) mg de Fe

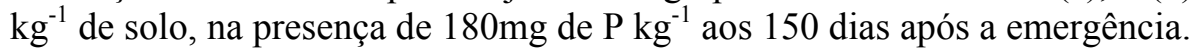

FIGURE 3: Coloration of leaves of young plants of grápia fertilized with 0 (a), 6 (b) and 12 (c) $\mathrm{mg}$ of Fe $\mathrm{kg}^{-1}$ of soil, in the presence of $180 \mathrm{mg} \mathrm{P} \mathrm{kg}^{-1}$ at 150 days after emergence.

De forma interessante, o aumento da adubação fosfatada de 60 para $180 \mathrm{mg} \mathrm{kg}^{-1}$ aumentou a concentração de $\mathrm{Fe}$ em todos órgãos da planta, sendo esse incremento na ordem de $8 \%, 35 \%$ e $47 \%$ respectivamente nas raízes, caule e folhas (Tabela 4). É importante ressaltar que a adubação utilizada diminuiu o pH do solo em 0,4 unidades (Tabela 1). Esse efeito pode responder pela maior disponibilidade do $\mathrm{Fe}$ e $\mathrm{Zn}$ no solo respectivamente em, aproximadamente, $24 \%$ e $38 \%$, enquanto as concentrações de $\mathrm{Cu}$ e $\mathrm{Mn}$ permaneceram quase-inalteradas (Tabela 1). Portanto, o aumento da absorção de Fe pela planta pode estar relacionado ao efeito do $\mathrm{pH}$ do solo na disponibilidade do Fe. Por outro lado, na presença de $180 \mathrm{mg}$ de $\mathrm{P} \mathrm{kg}^{-}$ ${ }^{1}$ de solo, de modo geral, a concentração de Fe nos tecidos diminuiu pelo incremento da adubação de Fe. Esse comportamento pode ser relacionado ao aumento na produção de biomassa (Figura 1c) que provocou efeito de diluição do Fe nos tecidos da planta. Já na presença de $60 \mathrm{mg} \mathrm{de} \mathrm{P} \mathrm{kg}^{-1}$ de solo, houve apenas redução da concentração de Fe no caule e folhas, quando a adubação de Fe foi aumentada de 6 para $12 \mathrm{mg}$ $\mathrm{kg}^{-1}$.

Segundo Silveira et al. (2000), as concentrações adequadas de Fe nas folhas de Eucalyptus spp. variam entre 65 e $125 \mathrm{mg} \mathrm{kg}^{-1}$. Portanto, as concentrações de $\mathrm{Fe}$ nas folhas de plantas jovens de grápia, registradas no presente trabalho (Tabela 4) e também por Fogaça (1999), Nicoloso et al. (1999) e Fortunato (2001), demonstram que essa espécie se distancia do Eucalyptus em sua exigência por Fe, porém se 
aproxima da Araucaria angustifolia (Bert.) O. Ktze. (Malavolta et al., 1997) que também é uma espécie nativa.

TABELA 4: Médias aritméticas das concentrações de ferro, cobre e zinco nos tecidos de plantas jovens de grápia, aos 150 dias após a emergência.

TABLE 4: Arithmetic mean of the iron, cooper and zinc contents in the tissues of young plant of grápia, at 150 days after emergence.

\begin{tabular}{|c|c|c|c|}
\hline $\begin{array}{l}\text { Doses de } \mathrm{P}-\mathrm{Fe} \\
\quad\left(\mathrm{mg} \mathrm{kg}^{-1}\right)\end{array}$ & Raiz & Caule & Folha \\
\hline \multicolumn{4}{|c|}{ Ferro no tecido $\left(\mathrm{mg} \mathrm{kg}^{-1}\right)$} \\
\hline $60-0$ & 360 & 26 & 33 \\
\hline $60-6$ & 374 & 30 & 37 \\
\hline $60-12$ & 377 & 22 & 31 \\
\hline Média & 370 & 26 & 34 \\
\hline $180-0$ & 427 & 40 & 64 \\
\hline $180-6$ & 412 & 36 & 41 \\
\hline $180-12$ & 360 & 29 & 44 \\
\hline Média & 400 & 35 & 50 \\
\hline \multicolumn{4}{|c|}{ Cobre no tecido $\left(\mathrm{mg} \mathrm{kg}^{-1}\right)$} \\
\hline $60-0$ & 7,4 & 2,2 & 1,7 \\
\hline $60-6$ & 8,9 & 2,3 & 1,4 \\
\hline $60-12$ & 6,0 & 2,2 & 1,2 \\
\hline Média & 7,4 & 2,2 & 1,4 \\
\hline $180-0$ & 7,5 & 2,2 & 2,3 \\
\hline $180-6$ & 8,1 & 1,6 & 1,7 \\
\hline $180-12$ & 6,5 & 2,1 & 1,4 \\
\hline Média & 7,4 & 2,0 & 1,8 \\
\hline \multicolumn{4}{|c|}{ Zinco no tecido $\left(\mathrm{mg} \mathrm{kg}^{-1}\right)$} \\
\hline $60-0$ & 113 & 27 & 16 \\
\hline $60-6$ & 114 & 39 & 26 \\
\hline $60-12$ & 85 & 27 & 24 \\
\hline Média & 104 & 31 & 22 \\
\hline $180-0$ & 131 & 22 & 23 \\
\hline $180-6$ & 102 & 27 & 26 \\
\hline $180-12$ & 91 & 41 & 22 \\
\hline Média & 108 & 30 & 24 \\
\hline
\end{tabular}

alto nível de $\mathrm{P}$ no solo, temperaturas extremas, diferenças genéticas, baixo conteúdo de matéria orgânica em solos ácidos e $\mathrm{CaCO}_{3}$ livre (Lucas e Knezek, 1977). Desses fatores, pode-se inferir como tendo influenciado no estabelecimento da deficiência de Fe na grápia, o alto nível de P no solo (Tabela 1) por causa da adubação realizada, baixo conteúdo de matéria orgânica (Tabela 1) e a alta temperatura do ambiente.

Similarmente ao observado por Fogaça (1999) e Nicoloso et al. (1999), as raízes apresentaram a maior concentração de $\mathrm{Cu}$, sendo de, respectivamente, 3,5 e 4,5 vezes maior da encontrada no caule e folhas (Tabela 4). A concentração de $\mathrm{Cu}$ nas raízes e caule foram de, respectivamente, $50 \%$ e $93 \%$ maiores do que aquelas registradas por Nicoloso et al. (1999), enquanto nas folhas foram 116\% menores.

De modo geral, as concentrações de $\mathrm{Cu}$ nas raízes e caule não foram alteradas pela adubação fosfatada. Já nas folhas, a adubação de $180 \mathrm{mg}$ de $\mathrm{P} \mathrm{kg}^{-1}$ de solo aumentou em $29 \%$ a concentração de $\mathrm{Cu}$ (Tabela 4). Diferentemente desses resultados, Spencer (1966) observou que a adubação fosfatada, associada à aplicação de quatro níveis de $\mathrm{Cu}\left(0\right.$ a $\left.250 \mathrm{mg} \mathrm{kg}^{-1}\right)$, reduziu a concentração de $\mathrm{Cu}$ nas raízes e folhas de mudas de Citrus reticulata Blanco 'Cleópatra', sendo que, nos casos em que o $\mathrm{Cu}$ se tornou tóxico para o crescimento das plantas, o $\mathrm{P}$ adicionado reduziu a toxidez de $\mathrm{Cu}$.

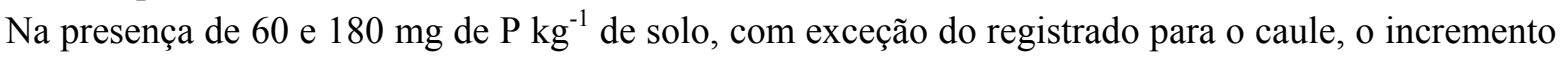


da adubação de 6 para $12 \mathrm{mg}$ de $\mathrm{Fe} \mathrm{kg}^{-1}$ de solo diminuiu a concentração de $\mathrm{Cu}$ nas raízes e folhas (Tabela 4). Em conseqüência da diminuição do $\mathrm{pH}$ do solo, fato associado ao efeito da adubação (Tabela 1) não ter alterado a disponibilidade do $\mathrm{Cu}$ (Tabela 1) e ter aumentado em $24 \%$ a do Fe (Tabela 1), sugere-se que houve interação desses dois micronutrientes na nutrição mineral da grápia.

Em geral, os seguintes fatores podem contribuir para a deficiência de $\mathrm{Cu}$ nas plantas: concentração de $\mathrm{Cu}$ em solos minerais inferior a $3 \mathrm{mg} \mathrm{kg}^{-1}$ e a alta disponibilidade de $\mathrm{P}, \mathrm{N}$ e $\mathrm{Zn}$ (Lucas e Knezek, 1977). Para Fernandes e Henriques (1991), a faixa adequada de concentração de $\mathrm{Cu}$ nos tecidos vegetais de espécies agrícolas situa-se entre 3 e $20 \mathrm{mg} \mathrm{kg}^{-1}$. Portanto, considerando a baixa concentração de Cu no solo (Tabela 1), o aumento da disponibilidade do $\mathrm{P}$ no solo pela adubação (Tabela 1), o decréscimo da concentração de $\mathrm{Cu}$ nos tecidos (Tabela 4) associado ao aumento da disponibilidade do Fe e $\mathrm{Zn}$ no solo (Tabela 1), quer pela diminuição do $\mathrm{pH}$ do solo ou pela adubação de $\mathrm{Fe}$, pode-se inferir que esses fatores caracterizam uma situação de deficiência de $\mathrm{Cu}$ na planta.

Semelhante ao constatado na concentração de $\mathrm{Fe}$ e $\mathrm{Cu}$, a concentração de $\mathrm{Zn}$ também foi maior nas raízes (Tabela 4). Resultado que corrobora aquele registrado por Fogaça (1999) e Nicoloso et al. (1999), porém estes autores verificaram uma diferença de concentração entre esses órgãos de, no mínimo, 100\% menor. Diferentemente do registrado para a concentração de $\mathrm{Fe}$ e $\mathrm{Cu}$, em geral, a concentração de $\mathrm{Zn}$ não foi afetada pelo incremento da adubação de $\mathrm{P}$, mesmo tendo ocorrido $35 \%$ de incremento na disponibilidade de $\mathrm{Zn}$ no solo (Tabela 1) pelo efeito da diminuição do $\mathrm{pH}$ (Tabela 1). Gianquinto et al. (2000) observaram que o aumento no suprimento de $\mathrm{P}$ diminuiu a concentração de $\mathrm{Zn}$ em Phaseolus vulgaris L., atribuindo a essa resposta o efeito de diluição pelo crescimento das plantas. Zhu et al. (2001), investigando duas cultivares de Triticum aestivum L., que se diferem pela eficiência de absorção de $\mathrm{P}$, verificaram que o aumento na disponibilidade de $\mathrm{P}$ causou uma redução significativa na absorção de $\mathrm{Zn}$ por unidade de massa de raiz e na concentração de $\mathrm{Zn}$ em ambas as cultivares.

Na presença de $180 \mathrm{mg}$ de $\mathrm{P} \mathrm{kg}^{-1}$ de solo, a adubação de Fe diminuiu a concentração de Zn nas raízes, aumentou no caule e não alterou nas folhas (Tabela 4).

Segundo Malavolta et al. (1997), as concentrações adequadas de Zn nas folhas de Eucalyptus spp. e Araucaria angustifolia são de, respectivamente, 50 e $5 \mathrm{mg} \mathrm{kg}^{-1}$. Portanto, as concentrações de Zn nas folhas de plantas jovens de grápia, registradas no presente trabalho (Tabela 4), são intermediárias em comparação a essas duas espécies. Entretanto, a concentração média de $23 \mathrm{mg}$ de $\mathrm{Zn} \mathrm{kg}^{-1}$ de massa seca folha (Tabela 4) corresponde à metade daquela observada em grápia por Nicoloso et al. (1999), Fogaça (1999) e Fortunato (2001).

Tomando todos esses resultados em conjunto, a folha foi o órgão da planta que apresentou a maior variação nas concentrações de $\mathrm{P}, \mathrm{Fe}, \mathrm{Cu}$ e $\mathrm{Zn}$ pelo aumento da adubação fosfatada. Dos três micronutrientes analisados, o Fe foi aquele que apresentou a maior variação em todos os órgãos da planta, seguido do $\mathrm{Cu}$ e do $\mathrm{Zn}$.

Tanto a concentração de $\mathrm{P}$ como a de Fe nos tecidos da planta aumentaram pelas doses crescentes da adubação fosfatada, porém esses incrementos não foram proporcionais, resultando numa relação de concentração de $\mathrm{P} / \mathrm{Fe}$ que beneficiou drasticamente o $\mathrm{P}$ em todos órgãos da planta (Tabela 5).

$\mathrm{Na}$ presença de $180 \mathrm{mg} \mathrm{kg}^{-1}$ de solo, as relações de concentração de $\mathrm{P} / \mathrm{Fe}$ nas raízes, caule e folhas aumentaram em média, respectivamente, 1,8, 2,0 e 2,3 vezes em comparação àquelas registradas pelo efeito de $60 \mathrm{mg}$ de $\mathrm{P} \mathrm{kg}^{-1}$ de solo (Tabela 5). A adubação de $\mathrm{Fe}$, apesar de diminuir os sintomas visuais da deficiência de Fe nas folhas (Figura 3) e aumentar a produção de biomassa (Figura 2c), não minimizou a diferença entre as concentrações desses nutrientes, refletindo-se no aumento da relação P/Fe (Tabela 5). Várias investigações têm mostrado que as folhas podem mostrar sintomas de deficiência de Fe mesmo que contenham concentrações de Fe mais altas do que folhas verdes (Olsen, 1977; Carter, 1980; Malavolta, 1980; Mengel e Malissiovas, 1981; Sahu et al., 1987). Watanabe et al. (1965) observaram que a concentração de $\mathrm{Fe}$ nos tecidos foliares de milho (Zea mays L.) não foi alterada pelo aumento da adubação fosfatada, porém a relação de concentração entre os dois elementos tornou-se elevada, provocando cloroses. Também Olsen (1977) relata que à medida que a concentração de $\mathrm{P}$ aumenta na planta ocorre uma indisponibilização do $\mathrm{Fe}$ nos tecidos, ou seja a planta não deixa de absorver $\mathrm{Fe}$, porém a relação de concentração entre $\mathrm{P} / \mathrm{Fe}$ aumenta em larga escala, fazendo com que o $\mathrm{P}$ retenha o $\mathrm{Fe}$ nas nervuras foliares e, assim, tornando-as cloróticas por 
causa da baixa produção de clorofila.

Em nível celular, a relação entre $\mathrm{P}$ e Fe parece estar relacionada com a variação do $\mathrm{pH}$ do meio apoplástico e do potencial eletroquímico, pelo qual a absorção do fósforo inorgânico $\left(\mathrm{H}_{2} \mathrm{PO}_{4}{ }^{-}\right)$, por ser impulsionada pelo transporte ativo secundário utilizando-se do gradiente de $\mathrm{H}^{+}$, ocasiona o aumento do $\mathrm{pH}$ apoplástico (Sakano et al., 1992) e, conseqüentemente, uma imobilização do Fe nesses espaços. Kosegarten e English (1994) encontraram uma relação inversa entre a concentração de clorofila e o pH do apoplasto foliar de soja (Glycine max L). Trabalhos conduzidos com beterraba (Beta vulgaris L.) constataram que a elevação do $\mathrm{pH}$ do apoplasto celular diminuiu a atividade da enzima Fe-redutase, pela alcalinização do meio apoplástico, ocasionando a formação de "pools" indisponíveis de Fe no meio externo (Gonzáles-Vallejo et al., 2000).

$\mathrm{Na}$ presença de $180 \mathrm{mg}$ de $\mathrm{P} \mathrm{kg}^{-1}$ de solo, as relações de concentração de $\mathrm{P} / \mathrm{Cu}$ nas raízes, caule e folhas aumentaram em média, respectivamente, 2,0, 3,2 e 2,6 vezes em comparação àquelas registradas pelo efeito de $60 \mathrm{mg}$ de $\mathrm{P} \mathrm{kg}^{-1}$ de solo (Tabela 5). Comportamento semelhante foi observado na relação de $\mathrm{P} / \mathrm{Zn}$, porém, nas folhas, o aumento de aproximadamente 2,9 vezes, foi o maior constatado nesse órgão da planta (Tabela 5).

TABELA 5: Relação de concentração entre o fósforo e os micronutrientes ferro, cobre e zinco nos tecidos de plantas jovens de grápia, aos 150 dias após a emergência.

TABLE 5: Ratio between the contents of phosphorus and the micronutrients iron, copper and zinc in the tissues of young plants of grápia, at 150 days after emergence.

\begin{tabular}{|c|c|c|c|}
\hline $\begin{array}{c}\text { Doses de } \mathrm{P}-\mathrm{Fe} \\
\left(\mathrm{mg} \mathrm{kg}^{-1}\right)\end{array}$ & Raiz & Caule & Folha \\
\hline \multicolumn{4}{|c|}{$\mathrm{P} / \mathrm{Fe}$} \\
\hline $60-0$ & 2,2 & 15 & 33 \\
\hline $60-6$ & 2,1 & 13 & 29 \\
\hline $60-12$ & 2,1 & 18 & 35 \\
\hline Média & 2,2 & 16 & 32 \\
\hline $180-0$ & 3,7 & 27 & 56 \\
\hline $180-6$ & 3,9 & 30 & 88 \\
\hline $180-12$ & 4,4 & 38 & 81 \\
\hline Média & 4,0 & 32 & 75 \\
\hline \multicolumn{4}{|c|}{$\mathrm{P} / \mathrm{Cu}$} \\
\hline $60-0$ & 108 & 177 & 653 \\
\hline $60-6$ & 90 & 174 & 784 \\
\hline $60-12$ & 132 & 182 & 898 \\
\hline Média & 110 & 178 & 779 \\
\hline $180-0$ & 212 & 494 & 1584 \\
\hline $180-6$ & 198 & 684 & 2070 \\
\hline $180-12$ & 247 & 511 & 2471 \\
\hline Média & 219 & 563 & 2042 \\
\hline \multicolumn{4}{|c|}{$\mathrm{P} / \mathrm{Zn}$} \\
\hline $60-0$ & 7,1 & 15 & 70 \\
\hline $60-6$ & 7,0 & 10 & 41 \\
\hline $60-12$ & 9,4 & 15 & 46 \\
\hline Média & 7,8 & 13 & 52 \\
\hline $180-0$ & 12 & 49 & 159 \\
\hline $180-6$ & 16 & 40 & 136 \\
\hline $180-12$ & 18 & 27 & 162 \\
\hline Média & 15 & 38 & 152 \\
\hline
\end{tabular}

Apesar de existir uma certa proporcionalidade no aumento da relação de concentração entre $\mathrm{P} / \mathrm{Cu} \mathrm{e}$ $\mathrm{P} / \mathrm{Zn}$, semelhante àquela observada para $\mathrm{P} / \mathrm{Fe}$ nos órgãos da planta, constatou-se que o aumento da adubação fosfatada alterou de modo mais marcante as relações de $\mathrm{P} / \mathrm{Cu}$ e $\mathrm{P} / \mathrm{Zn}$ no caule e folhas, fato que demonstra a 
possibilidade de ter ocorrido um somatório de deficiências de $\mathrm{Cu}, \mathrm{Zn}$ e $\mathrm{Fe}$, induzido pelo aumento da disponibilidade de P no solo e na planta. Estudos relatados por Reissmann e Wisnewski (2000), também indicam uma forte correlação negativa entre o aumento da relação $\mathrm{P} / \mathrm{Zn}$ e o crescimento de Pinus teada L.

Desse modo, fica evidente que a relação da concentração do P, com a dos micronutrientes catiônicos analisados, é de crucial importância para um adequado balanceamento nutricional da planta, corroborando com as observações de Watanabe et al. (1965), Olsen, (1977), Marschner, (1995), Reissmann e Wisnewski (2000), Zhu et al. (2001).

\section{CONCLUSÕES}

A relação de concentração entre o $\mathrm{P}$ e os micronutrientes $\mathrm{Fe}, \mathrm{Cu}$ e $\mathrm{Zn}$ é mais apropriada na avaliação do estado nutricional da grápia que a análise da concentração absoluta desses elementos nos tecidos.

A alta disponibilidade de $\mathrm{P}$ no solo causou deficiência de $\mathrm{Fe}, \mathrm{Cu}$ e $\mathrm{Zn}$ em plantas jovens de grápia.

$\mathrm{O}$ aumento da disponibilidade de $\mathrm{Fe}$, ocasionado pela adubação desse elemento, ou pela diminuição do $\mathrm{pH}$ do solo, induzida pela adubação com outros nutrientes, provocou decréscimo nas concentrações de $\mathrm{Cu}$ e Zn nas raízes.

Na presença de $180 \mathrm{mg}$ de $\mathrm{P} \mathrm{kg}^{-1}$ de solo, a aplicação de $12 \mathrm{mg}$ de $\mathrm{Fe} \mathrm{kg}^{-1}$ de solo, na forma de Fe-EDTA, diminuiu a clorose foliar e aumentou o crescimento de plantas jovens de grápia.

\section{AGRADECIMENTOS}

À PAPERGS, CNPq, CAPES e FIPE/UFSM pelo suporte financeiro.

\section{REFERÊNCIAS BIBLIOGRÁFICAS}

BIDDULPH, O.; WOODBRIDGE, C.G. The uptake of phosphorus by bean plants with particular reference to the effects of iron. Plant Physiology, Rockville, v. 27, p. 431-444, 1952.

BRASIL. Levantamento de reconhecimento dos solos do Estado do Rio Grande do Sul. Recife: Ministério da Agricultura - Departamento Nacional de Pesquisa Agropecuária - Divisão de Pesquisas Pedológicas, 1973. 431p. (Boletim Técnico, 30)

CARTER, M.R. Association of cation and organic anion accumulation with iron chlorosis of Scot pine on prairie soils. Plant and Soil, Dordrecht, v. 56, p. 291-299, 1980.

EMBRAPA. Serviço nacional de levantamento e conservação do solo: manual de métodos e análise de solos. Rio de Janeiro, 1979. 650p.

FERNANDES, J.C.; HENRIQUES, F.S. Biochemical, physiological, and structural effects of excess copper in plants. The Botanical Review, Bronx, v. 57, n. 3, p.246-273, 1991.

FOGAÇA, M.A.F. Nutrição mineral da grápia (Apuleia leiocarpa Vog. Macbride): Resposta à fertilização NPK em solo podzólico vermelho amarelo. 1999. 80p. Dissertação (Mestrado em Agronomia) - Universidade Federal de Santa Maria, Santa Maria, 1999.

FORTUNATO, R.P. pH do solo e toxidez de alumínio no crescimento e nutrição mineral de mudas de grápia (Apuleia leiocarpa). 2001. 59p. Dissertação (Mestrado em Agronomia) - Universidade Federal de Santa Maria, Santa Maria, 2001.

GIANQUINTO, G.; ABU-RAYYAN, A.; TOLA, L.D. et al. Interaction effects of phosphorus and zinc on photosynthesis, growth and yield of dwarf bean grown in two environments. Plant and Soil, Dordrecht, v. 220, p. 219-228, 2000.

GONZÁLEZ-VAREJO, E.B.; MORALES, F.; CISTUÉ, L. et al. Iron deficiency decreases the Fe(III)-chelate reducing activity of leaf protoplasts. Plant Physiology, Rockville, v. 122, p. 1-8, 2000.

KOSEGARTEN, H.; ENGLISCH, G. Effect of various nitrogen forms on the $\mathrm{pH}$ in leaf apoplast and on iron chlorosis of Glycine max L. Zeitschrift fuer Pflanzenernaehrung und Bodenkunde, Weinheim, v. 157, p. 401-405, 1994.

KOSEGARTEN, H.U.; HOFFMANN, B.; MENGEL, K. Apoplastic $\mathrm{pH} \mathrm{Fe}{ }^{3+}$ reduction in intact sunflower leaves. Plant Physiology, Rockville, v. 121, n. 4, p. 1069-1079, 1999.

LUCAS, R.E.; KNEZEK, B.D. Climatic and soil conditions promoting micronutrient deficiencies in plants. In: MORTVEDT, J.J.; GIORDANO, P.M.; LINDSAY, W.L. (Ed.). Micronutrients in agriculture. Madison: Soil Science 
Society of America, 1977. Cap.12. p. 265-288.

MALAVOLTA, E. Elementos de nutrição mineral de plantas. São Paulo: Agronômica Ceres, 1980. 251p.

MALAVOlTA, E.; VITTI, G.C.; OlIVEIRA, S.A. Avaliação do estado nutricional das plantas: princípios e aplicações. Piracicaba: Ed. Associação Brasileira para a Pesquisa da Potassa e do Fosfato, 1997. 319p.

MARSCHNER, H. Mineral nutrition of higher plants. London: Academic Press, 1995. 890p.

MATTOS, N.F.; GUARANHA, J. Contribuição ao estudo da grápia (Apuleia leiocarpa). Porto Alegre: Instituto de Pesquisas de Recursos Naturais Renováveis “AP”, 1983. 25p. (Boletim Técnico 12)

MENGEL, K.; MALISSIOVAS, N. Bikarbonat als auslösender Faktor der Eisenchlorose bei der Weinrebe (Vitis vinifera). Vitis, Siebeldingen, v. 20, p. 235-243, 1981.

MISSIO, E.L. Nutrição mineral da grápia (Apuleia leiocarpa Vog. Macbride) com fósforo, enxofre e ferro num ARGISSOLO VERMELHO Distrófico arênico. 2002. 66p. Dissertação (Mestrado em Agronomia) - Universidade Federal de Santa Maria, Santa Maria, 2002.

NICOLOSO, F.T.; GARLET, A.; ZANCHETTI, F. et al. Efeito de métodos de escarificação na superação da dormência de sementes e dois substratos na germinação e no desenvolvimento da grápia (Apuleia leiocarpa). Ciência Rural, Santa Maria, v. 27, n. 3, p. 419-424, 1997.

NICOLOSO, F.T.; ZANCHETTI, F.; GARLET, A. et al. Exigências nutricionais da grápia (Apuleia leiocarpa Vog. Macbride) em solo Podzólico vermelho amarelo. Ciência Rural, Santa Maria, v. 29, n. 2, p. 225-231, 1999.

NICOLOSO, F.T.; FOGAÇA, M.A.F; ZANCHETTI, F. et al. Nutrição mineral de mudas de grápia (Apuleia leiocarpa) em ARGISSOLO VERMELHO distrófico arênico: (I) Efeito da adubação NPK no crescimento. Ciência Rural, Santa Maria, v. 31, n. 6, p. 991-998, 2001.

OLSEN, S.R. Micronutrient interations. In: MORTVEDT, J.J.; GIORDANO, P.M.; LINDSAY, W.L. (Ed.). Micronutrients in agriculture. Madison: Soil Science Society of America, 1977. Cap.11. p. 243-264.

REISSMANN, C.B.; WISNEWSKI, C. Aspectos nutricionais de plantios de Pinus. In: GONÇALVES, J.L. de M.; BENEDETTI, V. (Ed.). Nutrição e fertilização florestal. Piracicaba: IPEF, 2000. Cap. 5. p.135-165.

REITZ, R.; KLEIN, R.M.; REIS, A. Projeto madeira do Rio Grande do Sul. Porto Alegre, Corag, 1988.

SAHU, M.P.; SHARMA, D.D.; JAIN, G.L. et al. Effects of growth substances, sequestrene 138-Fe and sulphuric acid on iron chlorosis of garden peas (Pisum sativun L.). Journal of Horticultural Science, Kent, v. 62, p. 391-394, 1987.

SAKANO, K.; YAZAKI, Y.; MIMURA, T. Cytoplasmic acidification induced by inorganic phosphate uptake in suspension cultured Catharanthus roseus cells. Plant Physiology, Rockville, v. 99, p. 672-680, 1992.

SPENCER, W.F. Effect of copper on yield and uptake of phosphorus and iron by citrus seedlings grown at various phosphorus levels. Soil Science, Baltimore, v. 102, p. 296-299, 1996.

SILVEIRA, R.L.V.A.; HIGASHI, E.N.; GONÇALVES, A.N. et al. Avaliação do estado nutricional do Eucalyptus: diagnose visual, foliar e suas interpretações. In: GONÇALVES, J.L. de M.; BENEDETTI, V. (Ed.). Nutrição e fertilização florestal. Piracicaba: IPEF, 2000. Cap. 3. p. 79-104.

TEDESCO, M.S.; GIANELLO, C.; BISSANI, C.A. et al. Análise de solo, plantas e outros materiais. Porto Alegre: Universidade Federal do Rio Grande do Sul, 1995. 174p. (Boletim Técnico 5)

TENNANT, D.A. A test of a modified line intersect method of estimating root lenght. Journal of Ecology, Oxford, v. 63, n. 3, p. 995-1001, 1975.

WATANABE, F.S.; LINDSAY, W.L.; OLSEN, S.R. Nutrition balance involving phosphorus, iron and zinc. Soil Science Society American Procedings, Madison, v. 29, p. 562-565, 1965.

ZHU, Y.-G.; SMITH, S.E.; SMITH, F.A. Zinc (Zn)-phosphorus (P) interactions in two cultivars of spring wheat (Triticum aestivum L.) differing in P uptake efficiency. Annals of Botany, London, v. 88, p. 941-945, 2001. 